\title{
PENGARUH SENAM BUGAR LANSIA TERHADAP TEKANAN DARAH PADA LANSIA DENGAN HIPERTENSI DI PUSKESMAS BURNEH BANGKALAN
}

\author{
The Effect of Elderly Fit Gymnastics To The Blood Pressure On Elderly People With \\ Hypertension In Puskesmas Burneh Bangkalan \\ ${ }^{1}$ Diah Jerita Eka Sari, Mardiana ${ }^{2}$ \\ 1,2 \\ Program Studi Ilmu Keperawatan dan Ners Universitas Muhammadiyah Gresik

\begin{abstract}
Alamat Korespondensi: Program Studi Ilmu Keperawatan
\end{abstract} \\ Jl. Proklamasi No. 54, Trate, Gresik, Jawa Timur - Indonesia \\ E-mail:diahjes@umg.ac.id
}

\begin{abstract}
ABSTRAK
Lanjut usia rentan mengalami perubahan,salah satunya pada sistem kardiovaskuler dengan penyakit yang sering terjadi berupa hipertensi. Salah satu faktor yang dapat mempengaruhi terjadinya hipertensi adalahkurangnya aktivitas fisik. Tujuan penelitian ini menganalisis pengaruh Senam Bugar Lansia terhadap tekanan darah pada lansia dengan hipertensi di Puskesmas Burneh Bangkalan.

Desain penelitian pra eksperimental dengan metode one group pre-post test design. Populasi sebanyak 50 lansia hipertensi dan jumlah sampel sebanyak 45 lansia dengan teknik simple random sampling. Instrumen penelitian menggunakan lembar observasi dan pengukuran tekanan darah menggunakan sphygmomanometer dan stetoskop. Analisa data menggunakan uji Wilcoxon dengan SPSS 16.00 .

Sebelum melakukan senam bugar lansia sebagian besar mengalami hipertensi stadium 1 sebanyak 30 lansia (66,7\%), dan setelah melakukan senam bugar lansia hampir seluruh lansia mengalami hipertensi stadium 1 sebanyak 37 lansia $(82,2 \%)$, nilai uji statistik didapatkan hasil $\mathrm{p}=$ $0,002 \alpha=0,05$ maka $p<\alpha$ dan H1 diterima.

Ada pengaruh senam bugar lansia terhadap tekanan darah pada lansia dengan hipertensi di Puskesmas Burneh Bangkalan.
\end{abstract}

Kata Kunci : hipertensi, senam bugar lansia, lansia

\section{ABSTRACT}

The elderly people tended to experience changes, as on cardiovascular system which certain diseases would frequently appear, for example hypertension. A factor which could affect the emergence of hypertension was lack of physical activity. This research aimed to analyze the effect of elderly fit gymnastics to the blood pressure on elderly people with hypertension in Puskesmas Burneh Bangkalan.

This research exerted pre-experimental research method and one group pre-post-test design. The total population were 50 elderly people with hypertension, while the total sample were 45 elderly people through simple random sampling technique. The research instruments were observation sheet and measurement of blood pressure which used sphygmomanometer and stethoscope. The data of research was analyzed in Wilcoxon test through SPSS 16.00 program.

This research referred that before the implementation of elderly fit gymnastics, most of elderly people were in $1^{\text {st }}$ stadium of hypertension approximately 30 elderly clients $(66,7 \%)$, Whilst, after the implementation of fit gymnastics on elderly people, the total of elderly people who suffered hypertension: $1^{\text {st }}$ stadium of hypertension approximately 37 elderly clients $(82,2 \%)$. Based on the statistical test value, $p$ value $=0,002$ and $\alpha=0,05$, in short, $p<\alpha$ and H1 was approved.

This research indicated the effect of elderly fit gymnastics to the blood pressure on elderly people with hypertension in Puskesmas Burneh Bangkalan.

Keywords: hypertension, elderly fit gymnastics, elderly people 


\section{PENDAHULUAN}

Lanjut usia merupakan sebuah proses normal dari muda menjadi tua, dimana pada usia itu mengalami berbagai macam perubahan secara struktural maupun fungsional. Perubahan tersebut juga terjadi pada sistem kardiovaskuler dengan penyakit yang sering terjadi berupa hipertensi. Faktor-faktor yang dapat mempengaruhi terjadinya hipertensi adalah usia, keturunan, obesitas, merokok dan kurangnya aktivitas fisik seperti latihan fisik yang berupa tugas-tugas dirumah tangga dan bercocok tanam sederhana dan berkebun, berjalan-jalan, jalan cepat, berenang, bersepeda, dan senam. Hal ini terjadi karena adanya penurunan fungsi fisik yang menyebabkan lansia mudah mengalami kelelahan. Salah satu cara yang dapat diterapkan untuk meminimalisir kendala itu adalah dengan cara meningkatkan aktivitas fisik berupa senam seperti Senam Bugar Lansia, dimana Senam Bugar Lansia ini dapat mengontrol tekanan darah dan meningkatkan kualitas hidup penderita hipertensi.

Data World Health Organization 2015(WHO, 2015)mengindikasikan bahwa hampir 1,13 Miliar orang menderita hipertensi secara global, yang sama dengan 1 dari 3 orang di dunia didiagnosis mengalami hipertensi. Peningkatan yang terus menerus dari penderita hipertensi tiap tahun, hingga diestimasikan bahwa pada tahun 2025 penderita hipertensi bisa mencapai 1,5 Miliar orang, begitupun diestimasikan bahwa jumlah penderita yang berpotensi meninggal dunia sekitar 9,4 juta orang serta komplikasinya. Penyakit terbanyak pada usia lanjut berdasarkan Riset Kesehatan Dasar tahun 2018(Riskesdas, 2018) antara lain hipertensi (57,6\%), osteoartritis (51,9\%), masalah gigi dan mulut (19,1\%). Berdasarkan Riset Kesehatan Dasar tahun 2018penderita hipertensi di Madura mencapai 185.857 penderita, sedangkan prevalensi hipertensi berdasarkanRiskesdas tahun 2013 (Riskesdas, 2013)menyebutkan sebanyak $8,4 \%$ jumlah penderita hipertensi di Indonesia secara keseluruhan dan di Jawa Timur menyebutkan, total penderita hipertensi sebanyak $8,2 \%$.

Menurut data dari Riskesdas Jawa Timur menjelaskan keseluruhan prevalensi hipertensi di Jawa Timur pada tahun 2013 sebanyak $26,2 \%$ dan meningkat sebanyak $36,32 \%$ pada tahun 2018. Menurut data dari Dinas Kesehatan Bangkalan pada tahun 2018 mencapai 7.034 penderita hipertensi dan meningkat sebanyak 11.401 penderita hipertensi pada tahun 2019.

Data awal yang diperoleh dari Puskesmas Burneh diketahui pada tahun 2019 dari bulan Agustus hingga Oktober penderita hipertensi sebanyak 1.005 lansia angka ini mengindikasikan bahwa di Puskesmas Burneh jumlah penderita hipertensi sangat tinggi. Beberapa faktor yang dapat memicu tekanan darah tinggi atau hipertensi tersebut diantaranya adalah karena faktor lanjut usia, perubahan gaya hidup dan tidak sehatnya pola makan seperti berlebihan mengkonsumsi natrium dan kebiasaan merokok dan mengkonsumsi alkohol dan kurangnya latihan fisik atau berolahraga merupakan pemicu dari hipertensi(Lauralee, 2011).Selain itu hipertensi juga terjadi karena adanya perubahan pada 
sistem kardiovaskuler dimana akan terjadi penurunan pemompaan darah dijantung pada lansia, dan secara keseluruhan ukuran jantung juga mengalami penurunan denyut jantung menurun, pada lansia katup jantung akan lebih tebal dan kaku disebabkan lipid yang berakumulasi. Pada lansia peningkatan tekanan darah sistolik terjadi karena hilangnya distensibilitas arteri, sedangkan tekanan darah diastolik tetap sama atau meningkat (Mujahidullah, 2012).

Untuk membantu penurunan tekanan darah pada lansia harus mengubah gaya hidup yang salah menjadi benar dengan cara mengurangi konsumsi natrium, mengurangi merokok, mengurangi konsumsi alkohol, melakukan latihan fisik seperti berolahraga salah satunya berupa senam yang teratur bisa meminimalisir tingkat stres dan rasa cemas serta tingkat depresi. Penurunan tersebut merangsang kerja sistem saraf perifer khususnya parasimpatis yang dapat mengakibatkan terjadinya vasodilatasi penampang pembuluh darah dan juga menurunkan tekanan darah sistolik dan juga diastotik. Olahraga senam bugar lansia dengan teratur dapat memperlambat atau mencegah rusak atau hilangya fungsi organ. Disamping itu menurut banyak riset memperlihatkan bahwa olahraga senam lansia bisa menghilangkan bermacam potensi terjadinya penyakit seperti hipertensi, diabetes melitus, penyakit arteri koroner dan kecelakaan (Moniaga, Pangemanan, \& Rampengan, 2013).

Senam bugar lansia adalah serangkaian gerakan yang diatur dan diarahkan sesuai dengan kemampuan orang lanjut usia, aktivitas olahraga bisa memperkuat kemampuan tubuh akan menjaga kesehatan mulai dari menghilangkan faktor stres yang mengakibatkan tekanan darah naik, kemudian senam bugar ini dapat dijadikan sebagai upaya penyembuhan bagi penderita hipertensi yang bermanfaat dan juga terdapat unsur penenangan diri yang dapat menstabilkan tekanan darah dikarenakan didalam prosedur senam memiliki gerakan pemanasan dan juga pendinginan yang bertujuan untuk merilekskan tubuh kembali, oleh karena itu senam bugar lansia ini disarankan bagi penderita hipertensi disamping itu sebagai upaya pengobatan lain atau usaha pengobatan pendamping (Dalimartha, 2008 dalam (Zannah, 2017).

Dari uraian di atas, bahwa senam bugar lansia merupakan tindakan non-farmakologis yang dapat bisa dilakukan untuk membantu penurunan hipertensi pada lansia, maka peneliti tertarik untuk melakukan penelitian dengan judul "pengaruh senam bugar lansia terhadap tekanan darah pada lansia dengan hipertensi di Puskesmas Burneh Bangkalan”.

\section{METODE}

Desain yang digunakan dalam penelitian ini adalah pra eksperimental. Dengan metode one group pre-post test design. Cara pengambilan sampel dalam penelitian ini menggunakan teknik purposive sampling. Sampel dalam penelitian ini adalah lansia dengan Hipertensi di Puskesmas Burneh ditentukan dengan rumus Slovin, (Nursalam, 2013)peneliti mendapati 45 responden yang ditentukan menurut kriteria inklusi Lansia usia 60 tahun keatas di Puskesmas Burneh, Lansia 
yang hanya memiliki riwayat tekanan darah tinggi, lansia yang beralamat di sekitar wilayah kerja Puskesmas Burneh, lansia yang bersedia menjadi responden.

Dalam penelitian ini menggunakan lembar observasi pengukuran tekanan darah. Peneliti mengunjungi rumah lansia dalam 1 hari sebanyak 7 lansia. Langkah pertama lansia di ukur tekanan darah dengan alat ukur sphygmomanometer dan stetoskop sebelum melakukan senam. Setelah itu lansia melakukan senam bugar lansia selama 30 menit, setelah melakukan senam bugar lansia diukur lagi tekanan darahnya dengan alat ukur sphygmomanometer dan stetoskop, frekuensi melakukan senam bugar lansia ini 3 kali perminggu selama 3 minggu untuk melihat hasil pengaruh senam bugar lansia terhadap tekanan darah.

Untuk mengetahui pengaruh senam bugar lansia terhadap tekanan darah pada lansia dengan hipertensi diuji terlebih dahulu dengan menggunakan uji normalitas dengan tingkat signifikasinya $\mathrm{p} \geq 0.05$ sebelum dilakukan uji wilcoxon signed rank test yang akan diolah atau dihitung dengan menggunakan komputerisasi program SPSS 16 dengan tingkat kemaknaan $\alpha=0,05$ jika $\alpha<$ 0,05 maka $\mathrm{H} 1$ di terima yang artinya ada pengaruh senam bugar lansia terhadap tekanan darah pada lansia dengan hipertensi.

\section{HASIL DAN PEMBAHASAN}

Tabel 1 Distribusi Frekuensi Tekanan Darah Sebelum Diberikan Senam Bugar Lansia Di Puskesmas Burneh Tahun 2020

\begin{tabular}{lcc}
\hline Tekanan Darah & Frekuensi & $\%$ \\
\hline $\begin{array}{l}\text { Hipertensi } \\
\text { Stadium 1 }\end{array}$ & 30 & 66,7 \\
\hline $\begin{array}{l}\text { Hipertensi } \\
\text { Stadium 2 }\end{array}$ & 10 & 22,2 \\
\hline Hipertensi & 5 & 11,1 \\
Stadium 3 & & \\
\hline Total & 45 & 100 \\
\hline
\end{tabular}

Sumber data : Data primer (2020)

Dari hasil penelitian pada tabel 5.3 menunjukkan sebanyak 45 lansia, sebelum diberikan perlakuan senam bugar lansia, sebagian besar mengalami hipertensi stadium 1 dengan jumlah 30 lansia (66,7\%), dan hipertensi stadium 2 sejumlah 10 lansia (22.2\%), dan sebagian kecil hipertensi stadium 3 sejumlah 5 lansia (11.1\%).

Tabel 2 Distribusi Frekuensi Tekanan Darah Setelah Diberikan Senam Bugar Lansia Di Puskesmas Burneh Tahun 2020

\begin{tabular}{lcc}
\hline Tekanan Darah & Frekuensi & $\%$ \\
\hline $\begin{array}{l}\text { Hipertensi } \\
\text { Stadium 1 }\end{array}$ & 37 & 82,2 \\
\hline $\begin{array}{l}\text { Hipertensi } \\
\text { Stadium 2 }\end{array}$ & 6 & 13,3 \\
\hline $\begin{array}{l}\text { Hipertensi } \\
\text { Stadium 3 }\end{array}$ & 2 & 4,4 \\
\hline Total & 45 & 100 \\
\hline
\end{tabular}

Sumber data : Data primer (2020)

Hasil penelitian pada tabel 5.4 diketahui setelah diberikan perlakuan senam bugar lansia selama 3 kali perminggu dalam 3 minggu dengan waktu 30 menit, hampir seluruh responden memiliki tekanan darah hipertensi stadium 1 yaitu sebanyak 37 lansia $(82,2 \%)$, tekanan darah hipertensi stadium 2 sebanyak 6 lansia (13,3\%), dan sebagian kecil 
lansia memiliki tekanan darah hipertensi stadium 3 sebanyak 2 lansia $(4,4 \%)$.

Tabel 3 Perbedaan Tekanan Darah Sebelum Dan Setelah Diberikan Senam Bugar Lansia

\begin{tabular}{lcccc}
\hline \multirow{2}{*}{ Hipertensi } & \multicolumn{2}{c}{ Sebelum } & \multicolumn{2}{c}{ Sesudah } \\
\cline { 2 - 5 } & $\mathrm{F}$ & $\%$ & $\mathrm{~F}$ & $\%$ \\
\hline Hipertensi & 30 & 66,7 & 37 & 82,2 \\
Stadium 1 & & & & \\
\hline $\begin{array}{l}\text { Hipertensi } \\
\text { Stadium 2 }\end{array}$ & 10 & 22,2 & 6 & 13,3 \\
\hline $\begin{array}{l}\text { Hipertensi } \\
\text { Stadium 3 }\end{array}$ & 5 & 11,1 & 2 & 4,4 \\
\hline Total & 45 & 100 & 45 & 100 \\
\hline
\end{tabular}

Sumber data : Data primer (2020)

Berdasarkan tabel 3 menunjukkan bahwa lansia yang mengalami hipertensi stadium 1 sebelum melakukan senam bugar lansia sebanyak 30 lansia $(66,7 \%)$ dan setelah melakukan senam bugar lansia mengalami peningkatan sebanyak 37 lansia $(82,2 \%)$, lansia yang mengalami hipertensi stadium 2 sebelum melakukan senam bugar lansia sebanyak 10 lansia $(22,2 \%)$ sedangkan setelah melakukan senam bugar lansia mengalami penurunan menjadi 6 lansia $(13,3 \%)$, dan lansia yang mengalami hipertensi stadium 3 sebelum melakukan senam bugar lansia sebanyak 5 lansia $(11,1 \%)$ sedangkan setelah melakukan senam bugar lansia mengalami penurunan menjadi 2 lansia $(4,4 \%)$.

\section{KESIMPULAN}

Dari hasil penelitian pengaruh senam bugar lansia terhadap tekanan darah di simpulkan bahwa terjadi penurunan tekanan darah pada lansia yang melakukan senam bugar lansia dengan nilai kemaknaan $\mathrm{p}=$ 0,002 .

\section{SARAN}

Sebaiknya dilakukan penelitian lanjut dengan jumlah sampel yang lebih banyak dan waktu yang cukup lama agar dapat mengetahui perbedaan yang signifikan senam bugar lansia terhadap tekanan darah.

\section{DAFTAR PUSTAKA}

Lauralee, S. (2011). Fisiologi Manusia : Dari Sel Ke Sistem (6 ed.). Jakarta: EGC.

Moniaga, V., Pangemanan, D. H. C., \& Rampengan, J. J. V. (2013). Pengaruh Senam Bugar Lansia Terhadap Tekanan Darah Penderita Hipertensi Di Bplu Senja Cerah Paniki Bawah. E-Biomedik, Volume 1, Nomor 2, hlm. 785-789.

Mujahidullah, K. (2012). Keperawatan Geriatik : Merawat Lansia Dengan Cinta Dan Kasih Sayang. Yogyakarta: Pustaka Pelajar.

Nursalam. (2013). Metodologi Penelitian Ilmu Keperawatan. Jakarta: Salemba Medika.

Riskesdas. (2013). Riset Kesehatan Dasar Hipertensi 2013. Jakarta: Badan Litbangkes, Depkes RI.

Riskesdas. (2018). Riset Kesehatan Dasar Hipertensi 2018. Jakarta: Badan Litbangkes, Depkes RI.

WHO. (2015). World Health Statistic Report 2015. Geneva: World Health Organization 2015.

Zannah, M. (2017). Pengaruh Senam Bugar Lansia Terhadap Penurunan Tekanan Darah Pada Lansia Hipertensi Di Wilayah Kerja Puskesmas Bontang Selatan 1 Kota Bontang. Unpublished Skripsi, Universitas Muhammadiyah Kalimantan Timur, Kalimantan Timur. 